\title{
Formulating Agricultural Extension Planning Based on Farmer Achievement: The Case of Organic Rice Farming Risk Mitigation in Indonesia
}

\author{
Ujang Maman 1,*, Yusron Razak ${ }^{2}$, Murodi $^{3}$, Asep Saefuddin ${ }^{4}$, Faisal Hendra ${ }^{5}$, \\ Zirmansyah $^{6}$, Nindyantoro ${ }^{7}$, Lilis Imamah Ichdayati ${ }^{1}$, Junaidi ${ }^{1}$ \\ ${ }^{1}$ Agribusiness Program, Faculty of Science and Technology, Universitas Islam Negeri Syarif Hidayatullah Jakarta, Indonesia \\ ${ }^{2}$ Department of Sociology, Faculty of Social and Political Sciences, Universitas Islam Negeri Syarif Hidayatullah Jakarta, Indonesia \\ ${ }^{3}$ Muslim Community Development Program, Faculty of Da'wah and Communication, Universitas Islam Negeri Syarif Hidayatullah \\ Jakarta, Indonesia \\ ${ }^{4}$ Department of Statistics, IPB University, Indonesia \\ ${ }^{5}$ Faculty of Humanity, University of Al-azhar Indonesia, Indonesia \\ ${ }^{6}$ Faculty of Psychology and Education, University of Al-azhar Indonesia, Indonesia \\ ${ }^{7}$ Resource and Environment Department, Economic and Management Faculty, IPB University, Indonesia
}

Received December 1, 2021; Revised January 17, 2022; Accepted February 16, 2022

\section{Cite This Paper in the following Citation Styles}

(a): [1] Ujang Maman, Yusron Razak, Murodi, Asep Saefuddin, Faisal Hendra, Zirmansyah, Nindyantoro , Lilis Imamah Ichdayati, Junaidi, "Formulating Agricultural Extension Planning Based on Farmer Achievement: The Case of Organic Rice Farming Risk Mitigation in Indonesia," Universal Journal of Agricultural Research, Vol. 10, No. 1, pp. 64 - 76, 2022. DOI: 10.13189/ujar.2022.100106.

(b): Ujang Maman, Yusron Razak, Murodi, Asep Saefuddin, Faisal Hendra, Zirmansyah, Nindyantoro, Lilis Imamah Ichdayati, Junaidi (2022). Formulating Agricultural Extension Planning Based on Farmer Achievement: The Case of Organic Rice Farming Risk Mitigation in Indonesia. Universal Journal of Agricultural Research, 10(1), 64 - 76. DOI: 10.13189/ujar.2022.100106.

Copyright $\bigcirc 2022$ by authors, all rights reserved. Authors agree that this article remains permanently open access under the terms of the Creative Commons Attribution License 4.0 International License

\begin{abstract}
Currently, more than $65 \%$ of Indonesian farmers are at the age of 45 years or older. In next 30 years, it is estimated that Indonesia will experience a farmers' scarcity. The Indonesian government must raise millennial farmers who are relatively educated and have high creativity. But the coming of "new farmer" should be followed by changing agricultural extension model. The top-down extension is no longer suitable with basic characters of youth; they need a dialogical-participatory extension model which is based on their achievements. Therefore, by the case of mitigating organic rice farming system in Indonesia, this research aims to identify ORFS's risk mitigation attributes; achievement of mitigation implementation; and improvement priorities; and finally arrange agricultural extension planning based on this achievement. The sample of this research, by adopting Slovin Formula with less than 7\% error probability, is 109 organic rice farmers in West Java, Indonesia. The in-depth interviews prove six mitigation attributes in cultivation and plant maintenance phase.
\end{abstract}

Assisted by important-performance-analysis to determine farmer's achievement in implementation of these attributes, the agricultural extension planning should maintain the implementation of three attributes; remediate two attributes as main program, and extend the performance of one attribute as secondary program. The three attributes include promoting cultivation plant-based pesticide ingredient, training and outreach on manufacture and use of plant-based pesticides, and weeding plants without herbicides. The two attributes consist of socialization not to pollute organic agricultural land; and collaborate with relevant agencies to participate in the success of organic farming pilot project. The one attribute is giving sanctions for farmers who buy and use chemical inputs. The participatory extension model should be applied to implement above three kinds of extension planning.

Keywords Importance, Performance, Farmer Achievement, Extension Planning 


\section{Introduction}

The criticism of the "top down" and linear extension model has led to a participatory extension. In the linear model, the farmers are assumed to be only recipients of messages, as parties who must adopt innovations offered by various parties outside the farmers themselves, both from international and from authorized domestic institutions. The poor adoption of offered innovation as an output of agricultural extension planning is frequently addressed to the lack of farmers. The research of extension output, consequently, tends strongly to browse diversity of innovation adoption - or the low adoption of the offered practices - based on the internal or external diversity of farmers, such low motivation, less education level, and lack of experience. The farmer's categorization based on adoption of innovation into innovator, early adopter, early majority, late majority and laggard [4] was widely used prejudicially to ignite the farmers, especially in the case of unsuccessful extension.

The participatory of extension model is in contrary. Olayemi [22] describes in his research paper, the participatory extension is basically focussed on how the extension system is organized to lead the smallholder farmers to play a significant role in making the extension program, and also to encourage them to feel ownership of the extension program and extension activities. This focus of extension assumes the knowledge is acquired by interaction process, especially between the agent of extension and the progressive farmer. In the case Munding Village in Semarang Region of Central Java, Indonesia, indicates the high participation level of community does not merely arouse the knowledge about the importance of land ownership but also encourage the small farmer to prevent the massive land conversation from agriculture function to other usage [23].

Indeed, in the activity of agricultural extension, the farmer field school (FFS) indicates strongly the effectiveness of participation in disseminating the knowledge of pest and its predator and the harmful of pesticide use to kill the predator of pest which could probably cause the pest attack explosion due to the death of natural enemy of pest. Olayemi [22] emphasizes the participation model of FFS has successfully reduced the wide pesticide uses in Indonesia and Philippines. For more specific, in the case of onion farmer in Berebes, Central Java, the FFS has reduced the gap between the expected knowledge and acquired knowledge and the practical performance [9]. Therefore, the FFS which originally applied in Indonesia and Philippines in 1989, has been practised in more than 70 developing countries. Previously, the FFS is applied to encourage the farmer awareness about the harmful of pesticide and the importance of integrated pest management, but in the next the FFS has been adopted in many fields of extensions [22]. In Indonesia, the FFS is applied to develop farmer entrepreneurship [14] and small business holder promotion [13].

The FFS which is perceived as an ultimate participatory model of extension is characterized by a warm dialogue between the extension agent and the farmers in the equal position as participants. The extension is not diffusion of innovation but in contrary, the FFS lets the farmers aware about the problem, they are encouraged to solve the problem, and the farmer is given a chance to make a decision in finding the way out of the problems. In the case pest management, the farmers are welcome to make observations about plant-disturbing insects and natural enemies of pests. The extension is equipped by mini lab to observe the pest behavior and its natural enemy. If the number of predators is more than the plant disturbing pest, the farmers will conclude the unimportance of pesticide spraying; and oppositely they are aware about the harm of pesticide to kill the natural enemy.

The advantage of field school is of course recognized, but unfortunately the participation developed is merely instrumental for the success of programs initiated by various parties outside the farmers, and therefore it has not succeeded completely in avoiding top-down programs. Therefore, the preparation of extension planning should be based on the assumption that the farmer has achievements, both knowledge and practice, even though this knowledge is the result of a process of interaction with various parties, and is not the result of the full creativity of farmers. In the purpose of respecting farmers, the program points and the importance of these points must be left entirely to the farmers who will carry out these activities. In the context of Indonesia - and could probably the same with other countries - this type of agricultural extension model is strongly valuable in welcoming the presence of relatively educated millennial farmers who have quite good creativity. According to inter-census survey [2], $65.82 \%$ of Indonesian farmers have age more than 45 years old or older. It is estimated that within the next 30 years these farmers will disappear. The government must recruit millennial farmers who will replace them as food providers. At the same time, the extension model must be changed by accommodating their idea and creativity. The participatory extension models should be developed more broadly, but based on their ideas, creativity, and achievements.

Therefore, on the bases of organic rice farming risk, this research paper aims to identify the mitigation attributes, the farmer's perception about the importance of these attributes, their performance of implementation of these attributes; their achievement of this attribute's implementation; and the need of improvement of these attributes; and finally formulate the participatory extension planning based on this achievement. 


\section{Framework Analysis and Reasoning}

The risk and the risk of organic rice farming system must first be defined before further discussion about mitigation. The risk has a strong relationship with uncertainty and probability of unexpected result and consequence [16]. In line with this definition, Sotic and Rajic [19] explain, the risk could be defined based on the probability, expected value, uncertainty, and the objective of the action. The unsuccessful target is a risk indicated by the unpleasant result [19]. The risk could also be defined as a condition that has a possible adverse effect, and could happen in all conditions [9]. Omar and Din [21] -- for more clear -- present an important keyword of risk, in which it is the existence of "a negative impact." The level of unpleasant and disadvantage is of course relating to the management decision based on certain institution or individual condition. The level of lose for certain people is highly significant but for other, the degree of lose is in a low or medium level. The risk level is frequently based on people's view, in which the yield is not the same with the product which is planned [19]. The existence of non-halal food additive for halal food producer is a high risk that will make their production unlawful to consume.

The risk could be in the form of perception, attitude and behavior. The negative perception to the farming activities within the young people which induces farming unwillingness could be a risk to achieve the target of food self-sufficiency [10]. The strong tendency of farmer's children to sell the inherited rice field which induces the agricultural land conversion to other function outside the farming activity could strongly be perceived as risk in an effort of self-food providing [10]. The disobedience of animal butcher to the halal principle in the slaughtering process could bring in the halal risk for halal meat producer. The unable to trace ingredient of food in production process as well the unclear material of animal feed supplement could also be a risk that jeopardizes the halal status [8].

Regarding the risk of organic rice farming, it should refer to basic principle of this innovative practice. According to the International Federation of Organic Agriculture Movement (IFOAM) [5], based on the principle of healthy, the use of fertilizers, pesticides, animal drugs and food additives should not have an adverse health effect. It deeply means that the organic farming should avoid chemical input jeopardizing the human health and will threaten the quality and sustainability of environment and farming land. Referring to the principle of organic farming - directly or indirectly - The Simpatik Farmer Group Association (Gapoktan Simpatik) in Tasikmalaya. West Java, Indonesia emphasizes the organic farming practitioner should be able to make vegetable organic pesticide and have to use it in their daily farming practice. In addition, they have to understand the techniques of solid and liquid organic fertilizer making process in accordance with the principle of organic rice farming [11].

The basic principle of this organic farming could not be guaranteed to be implemented completely in farming practice. Gambelli et al. [6] in his studies about the certification process of organic farming in European Union (EU) found that the farmer's non-compliance (NCs) attitude occupies the second rank that jeopardizes the organic status of a product. The European Organic Certifier Council [3] also recognizes the less awareness of farmer about the importance of organic certification. The organic farmer in Indonesia is not highly different, in which the farmer awareness is relatively incomplete. Sriyadi [18] in his research in Special Region of Yogyakarta, Indonesia, found the majority of organic farming practitioners are still uncertified. The same research has also found, the organic farmer's awareness about the importance of certification is relatively low.

In this context, it also should be noted, suppose the organic famer practitioner has had a high discipline and has had strong compliance to the organic farming principle, also it does not guarantee to yield proper organic product. For the local context of Indonesia, although the Ministry of Agriculture has seriously encouraged the promotion of organic farming system because it is having benefit for better ecology and improving the quality of degraded land due to the continuous use of inorganic fertilizers [7]- it is not yet all farmers have adopted and implemented this innovative practice. The $95.2 \%$ of Indonesian farmer are still conventional, they commonly use chemical pesticide and fertilizer to maintain their vegetal from the probable attack of plant-disturbing organism [17]. These conventional farmers are frequently still in one stretch with the organic farming practitioner, they also have the same water flow, and are often neighbor to each other. Allahverdi et al. [28] emphasized in his research, the irrigation water has a serious effect on the agricultural soil. The organic farming in this condition could probably be contaminated by residue of chemical input. This is a serious risk. 


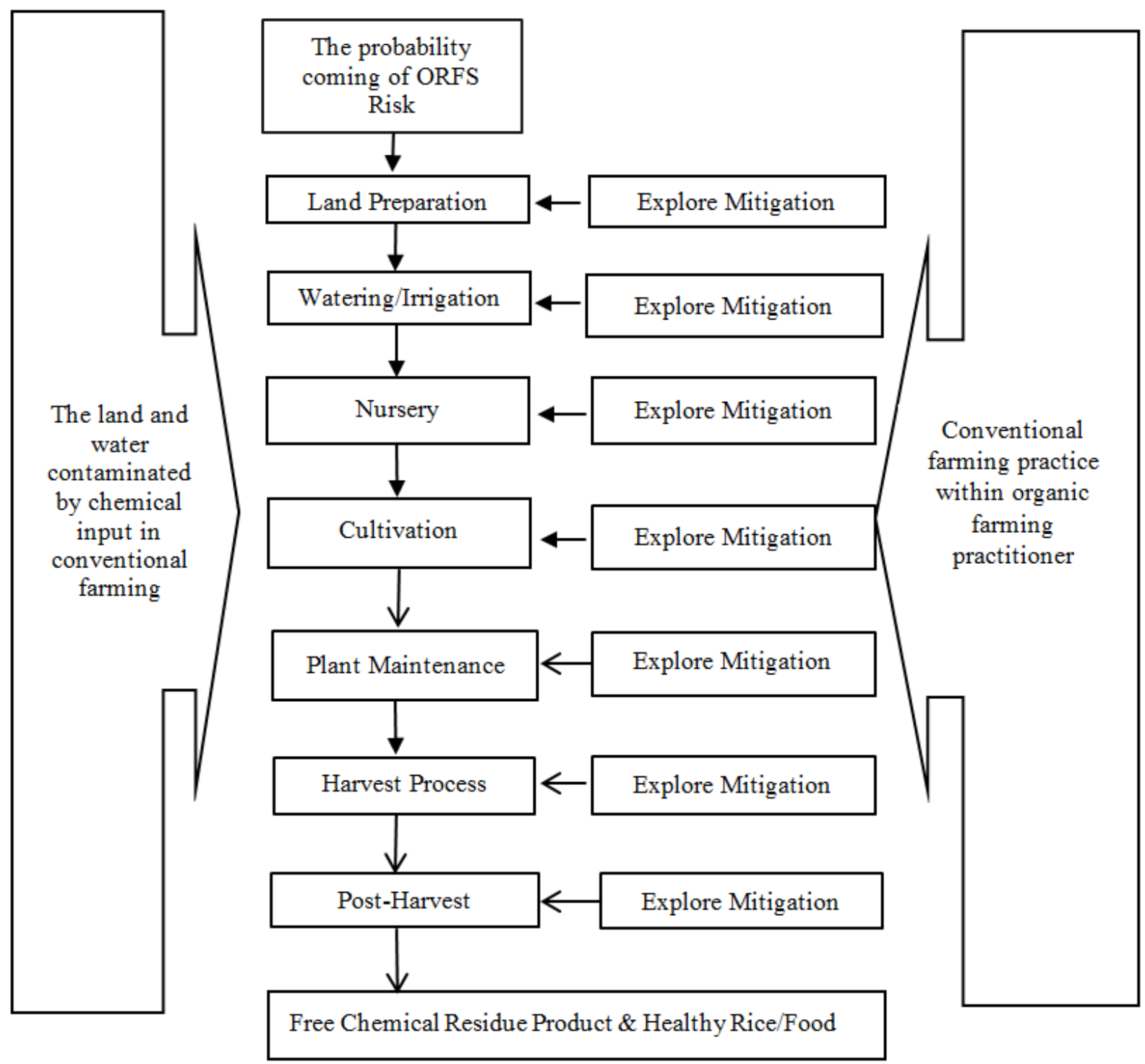

Figure 1. Framework Analysis to Mitigate Risk of Organic Rice Farming

The challenge for organic farmers is getting tougher by the case of chili farmers in Lampung Province, Indonesia. The farmers spray pesticide regularly without any consideration of insect and pest level as well as regardless of the existence of pests and diseases [27]. The conventional farmers commonly regard pesticide as a medicine which is valuable to avoid crop failure due to the pest attack and to increase the yield [20]. From this description, it is not surprising, the loyalty and satisfaction of conventional farmers to pesticides is still very high. The research of Mustikarini et al. [15] in Darmaga village, Bogor, West Java, Indonesia proved the customer satisfaction index of farmer to pesticide usage reaches $79.14 \%$ and the level of habitual buyer of this chemical input is $40 \%$.

Based on the above description, the organic process could probably be contaminated by the chemical input residue from a nearby farm by flowing water as well farming device which is previously used in conventional farming. This is seriously a risk that could nullify the organic status. The mitigation is valuable to yield the genuine organic product. The IFOAM has emphasized the importance of mitigation of organic farming. But, fortunately, according to IFOAM (2007), the mitigation should not merely by scientific approach. The farmer local wisdom should receive careful attention. The research conducted by Frayoga et al. [24] at Cheto Hamlet village in hinterland of Central Java indicates strongly the traditional farmers have indigenous local wisdom that could be adopted and developed to make harmony between people, environment, and farming practice.

Following the IFOAM's suggestion and the fact of indigenous local wisdom, this research paper assumes that organic farmer has their own way to mitigate the risk of organic rice farming system. However, the mitigation should be explored in each stage of farming process in supply chain approach [8], includes pre-cultivation stage, the stage of cultivation and plant maintenance, and the 
stage of crop and post-crop management, consisting of land preparation, watering/irrigation, nursery process, and source of seeds, cultivation, harvest and post-harvest treatment (Figure 1). The risk of organic farming could probably come in each stage, and the mitigation should of course cover completely the risk in all stages of farming. However, by paying attention the farmer's behavior in spraying pesticide which is commonly in plant maintenance, the mitigation is focused to the risk in cultivation and plant maintenance stage.

Based on the assumption that the farmers are mature, own local wisdom to mitigate the risk, and they also have an achievement in performing this mitigation, this research adopts the Importance performance analysis (IPA) model. Following this model, the research qualitatively explores mitigation attributes, measures the important and performance of the attributes, and concludes the farmer's achievement in this mitigation. In the IPA model, the achievement is defined as the suitability between the expectation and its performance in implementation of mitigation activities, which should be kept as good work [26].

\section{Material and Methods}

This research adopts the mix methods -- which is a combination between qualitative and quantitative survey -- by following the flow and logic of performance importance analysis (IPA). Therefore, this research starts with in-depth interview with prominent farmers in Simpatik United Farmer Group in Tasikmalaya, West Java, Indonesia to explore the action of mitigation that could be implemented in mitigating the risk of organic rice farming system based on their experience and their daily practice. This research calls the action of mitigation as mitigation attributes.

The next stage, this research explores the farmer view regarding their expectation and performance of implementation of the mitigation attributes. Thus, the research is a survey type, in which the population is 236 of practitioners of organic rice farming system gather in United Farmer Group of Simpatik in the above mentioned location. Based on Slovin formula in which the error probability is less than $7 \%$, the sample size is 109 respondents. The research's interviewees are determined by a proportional stratified random sampling technique.

The research as a quantitative survey measures the farmer perception about the importance and performance of each mitigation attribute by adopting four levels of Likert scale. Complying survey requirements, this research performs a validity and reliability test before data collecting. The Cronbach alfa which is adopted in this research proves 0.942 of reliability score which indicates the high reliability of the research's instrument.

Following the flow and logic of IPA model, this research adopts four stages of analysis, from categorization of attributes to the culmination analysis in mapping the mitigation attributes in Cartesian diagrams. The first stage adopts the following formula (1):

$$
\text { Interval }=\frac{\text { The higher Score }- \text { The lower Score }}{\text { Amount of Alternative Category }}
$$

In the light of this formula, the farmer's view about the expectation and performance of each mitigation attribute is categorized exclusively into high, medium, and low.

The counting of total score of each attribute and its average score - which is total score of each attribute divided by research respondents - is a second step in the IPA model. The third step is adopting the following formula to identify the suitability and gap between the importance and performance:

$$
T k i=\frac{\overline{X \imath}}{\bar{Y} \iota} \times 100 \%
$$

In which:

$T k i=$ Level of suitability

$\bar{X} \iota=$ Performance score

$\bar{Y} \iota=$ Importance score

The fourth step is providing the matrix of importance and performance level, and the matrix is divided into four columns of quadrants by adopting the following formula:

$$
\begin{gathered}
\overline{\bar{X}}=\frac{\sum_{i-1}^{N} \overline{x l}}{k} \\
\overline{\bar{Y}}=\frac{\sum_{i-1}^{N} \bar{y} \bar{l}}{k}
\end{gathered}
$$

Where:

$\overline{\bar{X}}=$ Average of the average of performance score

$\bar{Y}=$ Average of the average of importance score

$\mathrm{K}=$ The number of ORFR attributes

The fifth step is presenting each mitigation attribute in Cartesian diagram divided into four quadrants to determine the farmer's achievement in implementing the attributes, and to determine the level of priority of attribute's improvement based on the following formula:

$$
\bar{X}=\frac{\sum X i}{n} \quad \bar{Y}=\frac{\sum Y i}{n}
$$

Where:

$\bar{X}=$ Average of performance score

$\bar{Y}=$ Average of importance score

$\mathrm{n}=$ Amount of respondent

The first quadrant describes the high importance vs. low performance which indicates the needs of improvement. The second quadrant provides the attributes which high importance and performance indicate the achievement that needs to be maintained. The third quadrant represents low importance and low performance as a second priority of improvement; and the fourth quadrant presents high performance but low importance which indicates the probably overkill attributes and unimportance to plan. 


\section{Result and Discussion}

\subsection{Farmer Characteristic}

The respondents of this research are experienced farmer in organic rice farming. Most of them (59.64\%) have been practising the organic rice faming more than 10 years. More than $75 \%$ of interviewees have started this free-chemical input farming between years of 2006-2010. In addition, most of them (74.31\%) are agri-land owner, which will make them easier to make decision in farming practice, include taking the innovative practice and leaving the conventional habit especially in spraying the "poison" of pesticide. The desire to innovate is not surprising because of the relatively high education level. Most of respondents $(60.55 \%)$ have gotten the JHS (Junior High School) certificate or even acquired the higher level. But unfortunately, the organic rice practitioners are the old farmer. Almost all the farmers are 40s and older (Table 1), in which it needs young generation to continue this healthy practice. But despite these concerns, the organic farming practitioners are most likely skilled farmer; and they should be assumed to have good achievement in their practice. The agricultural extension planning should respect them, not to be confused with the novice farmers.

\subsection{Identification of Attributes Mitigation}

In the assumption that farmers have certain achievements in farming practice, the first stage of agricultural planning steps - of course following the IPA logic and model - should sharply identify these practices that should be adopted to mitigate the organic rice farming. The researchers in this research paper call them the attributes of mitigation. Based on in-depth interviews with prominent farmers gather in Simpatik united farmer groups in Tasikmalaya, West Java, Indonesia, this research paper presents six attributes, coded from X6 to X11 (Table 2). The attributes are generally to prevent using chemical input and develop farming skill to manufacture plant-based pesticides and herbicides.

Table 1. Respondent Characteristic

\begin{tabular}{|c|c|c|c|}
\hline Characteristic & Category & Freq & $\%$ \\
\hline \multirow{3}{*}{ Age } & $20-40$ years & 3 & 2.75 \\
\hline & $40>$ years & 106 & 97.25 \\
\hline & Sub Total & 109 & 100.00 \\
\hline \multirow{3}{*}{ Education Level } & JHS or more & 66 & 60.55 \\
\hline & ES or less & 43 & 39.45 \\
\hline & Sub Total & 109 & 100.00 \\
\hline \multirow{3}{*}{ Land Ownership } & Land Owner & 81 & 74.31 \\
\hline & Tenant & 28 & 25.69 \\
\hline & Sub Total & 109 & 100.00 \\
\hline \multirow{3}{*}{ Farming Experience } & $<10$ years & 44 & 40.36 \\
\hline & $>10$ years & 65 & 59.64 \\
\hline & Sub Total & 109 & 100.00 \\
\hline \multirow{4}{*}{ Starting Organic Farming } & $2000-2005$ & 18 & 16.51 \\
\hline & $2006-2010$ & 84 & 77.06 \\
\hline & $\geq 2011$ & 7 & 6.42 \\
\hline & Sub Total & 109 & 100.00 \\
\hline
\end{tabular}

Source: Primary data, processed (2020)

Table 2. Attributes Mitigation

\begin{tabular}{|c|l|}
\hline Code & Attributes of Organic Rice Farming Risk \\
\hline X6 & Promoting to cultivate the plant-based pesticide ingredients \\
\hline X7 & Training and outreach on the manufacture and use of plant-based pesticides \\
\hline X8 & Weeding plants without using herbicides \\
\hline X9 & Giving sanctions for farmers who buy chemical inputs, especially if farmers use them \\
\hline X10 & Socialization to the community not to pollute organic agricultural land with chemicals \\
\hline X11 & Collaborating with relevant agencies to participate in the success of the pilot project for organic farming \\
\hline
\end{tabular}


As commonly known, in organic farming process, all inputs and materials of cultivation must be labeled organic; and the risk would probably come if the material does not have the organic label and the farmer does not manufacture the input by themselves. Thus, to minimize this risk, the farmers are encouraged to make or plant materials for making fertilizers or vegetable pesticides independently so that the process can clearly be identified. That is why the first attribute mitigation is promoting to cultivate the plant-based pesticide ingredients (X6). The second attribute mitigation is intended to strengthen the use of organic material independently; and for this aim the farmers are encouraged to participate highly in a training of how to manufacture and use the plant-based pesticide (X7). The farmers are expected to be educated to make, implement, and familiarize the use of botanical ingredients.

The weeding is a step that must be done in plant maintenance. Unfortunately, the conventional farmers generally use herbicides to facilitate their process. But this practice risks contaminating agricultural land with chemicals. Therefore, this practice is strictly prohibited in organic rice farming. In this context the farmers are encouraged to weed without herbicide as the third attribute mitigation (X8). The fourth attribute - which is giving sanctions for farmers who buy chemical inputs and use them (X9) - is valuable to avoid the possibility of rogue farmers who secretly buy and use chemicals, even though they are practitioners of organic rice farming gathering in organic united farmer group.

In addition, another risk mitigation attribute is that socialization about the dangers of chemicals must be carried out continuously to remind farmer communities not to pollute their organic agricultural land (X10). This step is an effective mitigation action to produce genuine organic rice products. Thus, these actions are concluded in the list of attributes of organic rice risk mitigation. To strengthen the implementation of above attributes of organic risk mitigation, the organic rice farmers encourage collaborating with relevant agencies to participate in the success of the pilot project for organic farming (X11).

\subsection{The Farmer Expectation of Risk Mitigation Attributes}

Following the flow of IPA model, the research explores farmer perception about the importance or expectation of each mitigation's attributes. Fortunately, the farmers consider these attributes are important to implement in daily organic farming practice; and they also have a high expectation to adopt these attributes to yield the genuine organic rice products. This farmer's view is clearly indicated by a high level of average score. For more clear, this research adopts four levels of Likert scale with the key word is "expectation." The total score acquired from this measurement is divided by total samples, which yields an average score of each attribute's mitigation. The next step, the score obtained from this Likert scale is categorized into high, medium and low by applying the interval formula.

Referring to the data presented in Table 3 , it should be highlighted that the score of importance of mitigation attributes is varied, between 2.83 to 3.70 . However, the $\mathrm{X} 11$ attribute - in which it is the need to collaborate with relevant agencies to participate in the success of the pilot project for organic farming - should get a special attention. The farmer considers it as the more important aspect in mitigating the risk of organic rice farming, indicated by the highest score of expectation (3.70). This research's finding has reminded us to the classic work of Rogers [4] which emphasizes the importance of "observability" and "testability" in the idea or practice diffused to the community, especially for rural society. The new idea or practice - according to Rogers [4] - will be easier to adopt when the farmers have a chance to observe the result and to test the practice although in limited scope. Therefore, the pilot project for farming practice is considered as an important aspect in extension planning, including mitigation of organic rice farming.

Table 3. Attribute Mitigation, Expectation, Performance and Compatibility

\begin{tabular}{|c|c|c|c|c|c|c|c|c|}
\hline \multirow{2}{*}{ Mitigation Attributes } & \multirow{2}{*}{ Code } & \multicolumn{3}{|c|}{ Expectation } & \multicolumn{3}{|c|}{ Performance } & \multirow{2}{*}{$\begin{array}{c}\text { Comp } \\
(\%)\end{array}$} \\
\hline & & $\mathbf{S}$ & $\mathbf{A}$ & $\mathbf{C}$ & $\mathbf{S}$ & $\mathbf{A}$ & $\mathrm{C}$ & \\
\hline $\begin{array}{l}\text { Promoting the cultivation of plant-based pesticide } \\
\text { ingredients }\end{array}$ & X6 & 381 & 3.50 & $\mathrm{H}$ & 341 & 3.13 & $\mathrm{M}$ & 89.42 \\
\hline $\begin{array}{l}\text { Training and socialization of the manufacture and use of } \\
\text { plant-based pesticides }\end{array}$ & $\mathrm{X} 7$ & 386 & 3.54 & $\mathrm{H}$ & 344 & 3.16 & M & 89.26 \\
\hline Weeding plants without using herbicides & $\mathrm{X} 8$ & 378 & 3.47 & $\mathrm{H}$ & 350 & 3.21 & $\mathrm{H}$ & 92.50 \\
\hline $\begin{array}{l}\text { Giving sanctions for farmers who buy chemical inputs, } \\
\text { especially if farmers use them }\end{array}$ & $\mathrm{X} 9$ & 308 & 2.83 & M & 284 & 2.61 & M & 92.88 \\
\hline $\begin{array}{l}\text { Socialization to the community not to pollute organic } \\
\text { agricultural land with chemicals }\end{array}$ & $\mathrm{X} 10$ & 380 & 3.49 & $\mathrm{H}$ & 315 & 2.89 & M & 82.80 \\
\hline $\begin{array}{l}\text { Collaborating with relevant agencies to participate in the } \\
\text { success of the pilot project for organic farming }\end{array}$ & $\mathrm{X} 11$ & 403 & 3.70 & $\mathrm{H}$ & 299 & 2.74 & $\mathrm{M}$ & 74.05 \\
\hline Average of the Average & & & 3.42 & M & & 2.96 & M & 86.80 \\
\hline
\end{tabular}

Note: $\mathrm{S}=$ Score; $\mathrm{A}=$ Average; $\mathrm{C}=$ Category; Comp = Compatibility 
Another attribute that should get a high attention is the X9 which expresses the need of giving sanction for farmer who buys chemical inputs, especially for the farmers who use it. This attribute is in contrary with the previous attribute (X11). The first attribute gets a high score, but the later gets the lowest score of 2.83 , below the average of the average score of 3.42. The farmer seems to feel unwilling to impose the sanction for fellow farmers. This finding is not surprising because the relationship between farmers is commonly collegial. They are frequently neighboring each other in a good relationship and in a highly mutual understanding. More ever, they also gather in the same united farmer group. The previous research in West Java, Indonesia [12] proves the life of rural community is colored by mutual respect, good communication, partnership, and frequently has a family relationship. For farmers who are respondents of this research, moreover, they work together in the same farmer groups. Therefore, it is easy to catch why they have a high tendency not to impose the sanction from the farmer to collegial farmers. The sanction could be imposed by the outside authority.

\subsection{The Performance of Implementation of Risk Mitigation Attributes}

Other aspect that should get high attention is the similarities and differences between the importance and performance. The IPA model analysis is interested in identifying this level of similarities. The people who consider the something is important and they expect to implement it, they of course should have a high performance in its application. Unfortunately, this assumption does not come true for the case of mitigation of organic rice farming, which is the focus of this research The average of performance of each mitigation attribute is medium, with the score is varied, between 2.61 to 3.21 ; while the score of importance is between 2.83 to 3.70 (Table 3). Thus, in general, the average score of each attribute is lower than the farmer's view of its importance. From the six of mitigation attributes, this research finds merely one attribute which can be categorized into a high level of performance. The X8 attribute occupies the high category within other attributes. The attribute itself expresses the way of weeding plants without using herbicides. Therefore, on the basis of its score, this attribute is of course has become part of behavior of organic rice farming practitioners; and it is predicted as a farmer's achievement in a hard effort to yield the genuine status of organic rice.

In addition to above research finding, it should be emphasized, although the average score of performance is lower than the score of importance, but fortunately this research finds two attributes that are categorized into medium, but the scores of two attributes are above the average score of the average. The "training and socialization of the manufacture and use of plant-based pesticides" (X7) is mitigation attribute that acquires the score of 3.16, while the average of the average score is merely 2.94 (Table 3). Another attribute that gets score above the average of the average is X6, which reveals the importance of "Promoting cultivation of plant-based pesticide ingredients." The score of this X6 attribute is 3.13 , while the average score of the average as previously mentioned is 2.96 (Table 3 ).

This research finding is valuable but needs further steps of analysis. The attribute which gets high level of importance and performance - in IPA model analysis - is strongly predicted as an achievement in certain development program. Therefore, the X8 attribute hypothetically will occupy as a farmer achievement in extension program of organic rice farming. However, the two other attributes (X6 and X7) arouse the critical question, whether these attributes are categorized into farmer achievement which needs to maintain or in contrary they need high concentration to improve. Following the IPA flow and logic, this research fortunately will take further steps to answer this critical question on the basis of similarity and differences between the expectation and performance. The agricultural extension planning should be based on the result of this mapping.

\subsection{The Compatibility of Expectation and Performance}

Presenting data on the suitability and gaps in the IPA model is very important and should not be overlooked. The low gap between expectations and performance, between the level of interest in an object and the implementation of activities is a pretty good indicator of achievement. The conclusions generated from the IPA are actually based on expectations and performance. Logically, if all expectations are achieved in a program, then it is an achievement. On the other hand, if the gap is very wide between expectations and performance, the systematic action is needed to make various improvements. A researcher in Indonesia innovatively states, if the suitability is less than 89.11 percent, the various corrective actions are needed. Conversely, if the suitability is higher than 89.11 percent, it is necessary to make efforts to maintain this achievement [25]. In other words, a program is said to be successful if it the implementation reaches more than 89.11 percent.

Thus, the level of suitability in the planting and maintenance phase as shown in Table 3 is considered quite high with an average value of $86.8 \%$ which indicates that most of the farmers' expectations are in accordance with the performance of implementation.

In more detail, the attribute with the highest percentage of conformity is achieved by the attribute regarding the recommendation for sanctions for farmers who buy chemical inputs, especially if farmers use them (X9). This attribute has an average score of expectations in the 
medium category, and similarly the implementation performance of this attribute also gets an average score in the medium category as well. The attribute with the lowest percentage of conformity is obtained by the attribute about collaborating with the relevant agencies to participate in encouraging the organic farming pilot project (X11), which recorded a low suitability value of $74.05 \%$. The low level of suitability of this attribute is due to the high expectations of farmers for cooperation with related agencies as a form of support for the pilot project for the development of organic rice farming, which achieves an average of expected score of 3.70 which is categorized into the high level, and it is considered important by farmers. However, the implementation performance of this attribute is low with an average score of 2.74, and is in the medium category.

If referring to the theory of Sagala [25], in general, the implementation of organic rice farming mitigation still requires corrective action. This means the implementation of mitigation to produce genuine organic rice still requires a number of improvements. The corrective action, for more specific, is required for the $\mathrm{X} 10$-attributes which the score of compatibility is merely $82.80 \%$. The low of compatibility indicates the lack of socialization to the community about preventing not to pollute organic agricultural land with chemicals.

The X11 attributes is in accordance with the X10 attribute, but it is more strongly recommended for this attribute to get the corrective action. The attribute itself is regarding the recommendation to collaborate with relevant agencies to participate in encouraging the pilot project of organic farming. The score of compatibility of this attributes is strongly low, which is merely $74.05 \%$. The two attributes, therefore, could strongly be identified as the priority to get improvement in agricultural extension planning. However, in the light of above discussion, the mitigation of organic rice farming could probably provide three attributes as the farmer achievement indicated by high compatibility between the expectation and performance. The mapping of the attributes based on the expectation and performance is strongly needed to identify exactly which attributes need to improve and which of them are considered as the farmer achievement.

\subsection{Mapping of Attributes Mitigation}

Mapping of risk mitigation attributes is very important as a culmination in the IPA model to ensure which attributes fall into the category of farmer achievements that need to be maintained as the aim of this research. In line with this purpose, the mapping will also present which attributes need to be prioritized for improvement, as well as attributes that are second priority in extension planning, and attributes that do not need to be considered. This mapping is based on the average score of expectation (harapan) of each mitigation attribute which is laid in vertical line as an $\mathrm{X}$-axis, as well as the average of the average of performance (kinerja) of each attribute which is placed in horizontal line as Y-axis.

The average of the average score of importance and performance is the "key point" in this mapping. This is because the average of the average score of both importance and performance will make an intersection. Based on this "point of contact," the research could identify and categorize the mitigation attributes into four quadrants (Figure 2). The first quadrant describes the high importance of the attributes versus the low performance which indicates the needs of improvement of these attributes. The second quadrant identifies the attributes that acquire the high importance as well as high performance which determines that the attributes have been perfectly implemented in daily farming practice; and these attributes could certainly be concluded as the farmer achievement that needs to be maintained. The third quadrant describes the low importance and the low performance, which indicates in a planning of extension that these attributes take a category of second priority. The fourth quadrant takes a category of low importance and high performance which could be possibly overkilled in planning of agricultural extension.

This mapping process fortunately proves three mitigation attributes that could be categorized into farmer's achievement; two attributes take the position as main priority to improve in an agricultural extension; one attribute is as minor activity in a planning of improvement and fortunately this research gets the absence of the attributes that could be categorized into "possibly overkill" (Figure 2). The X6, X7, and X8 as previously predicted to take a position as farmer's achievement. In this context, it could be identified that the promotion of cultivation of plant-based pesticide ingredient has become a part of farmer's daily practice that should be appreciated. The training and socialization of the manufacture and use of plant-based pesticide have gotten a high support from the farmer and fortunately they also have perfectly implemented this practice. Another practice that has become a common behavior of the farmer is weeding plant without using herbicides.

In the other sides, the X10 and the X11 are the lack of farmer in their farming practice especially in performing the organic rice farming development. Therefore, the X10 and X11 need a strong improvement. The socialization to the community not to pollute organic agricultural land with chemicals is an important activity in farmer's perspective, but they unfortunately do not perform it yet perfectly in their practice to yield genuine organic rice. In line with this practice, the farmers are still lack in implementing collaboration with relevant agencies to participate in encouraging the pilot project for organic farming, although the farmers view this activity as important.

Another attribute that should get more attention is $\mathrm{X} 9$. Giving sanctions for farmers who buy chemical inputs, 
especially if farmers use them (X9) is unimportant in farmer's view, and accordingly the implementation of this attributes is lack. If the punishment is viewed as an important attribute in mitigating the risk of organic rice farming, it should be steps to make the farmer aware of the importance of this clause. Of course, it is an important aspect in planning of agricultural extension planning.

\subsection{Agricultural Extension Planning}

The advantages of participatory model of extension - which is represented by field school model - have widely been recognized within the extension services, practitioner, extension agent as well as within the extension experts. However, in the same condition, this model has the lack that should be improved, in which the extension planning, focus, and target are merely based on a program disseminated by institution outside the farmer, at home or abroad. In other sentence, the participatory model that widely socialized is merely instrumental to support the program outlined by the other sides.

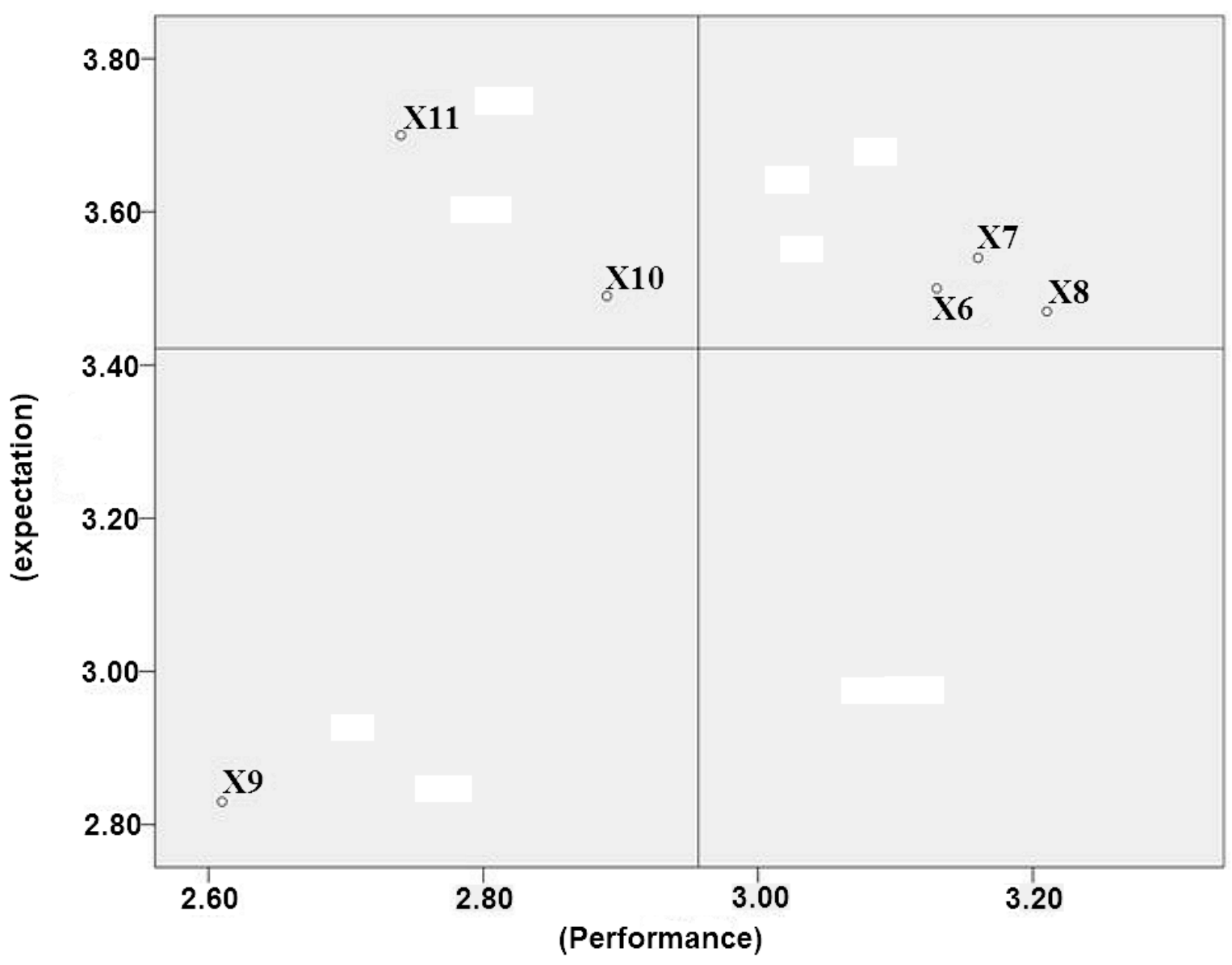

Figure 2. Four Quadrant of Mitigation Attributes

Table 4. The Target of Agricultural Extension Planning

\begin{tabular}{|c|c|c|c|c|c|c|}
\hline \multirow{2}{*}{ Mitigation Attributes } & \multirow[t]{2}{*}{ Code } & \multicolumn{4}{|c|}{ Quadrant } & \multirow{2}{*}{$\begin{array}{c}\text { Agricultural Extension } \\
\text { Planning }\end{array}$} \\
\hline & & $\mathbf{I}$ & II & III & IV & \\
\hline Promoting the cultivation of plant-based pesticide ingredients & $\mathrm{X} 6$ & & $\sqrt{ }$ & & & Planning to maintain \\
\hline $\begin{array}{l}\text { Training and socialization of the manufacture and use of } \\
\text { plant-based pesticides }\end{array}$ & $\mathrm{X} 7$ & & $\sqrt{ }$ & & & Planning to maintain \\
\hline Weeding plants without using herbicides & $\mathrm{X} 8$ & & $\sqrt{ }$ & & & Planning to maintain \\
\hline $\begin{array}{l}\text { Giving sanctions for farmers who buy chemical inputs, } \\
\text { especially if farmers use them }\end{array}$ & X9 & & & $\sqrt{ }$ & & $\begin{array}{l}\text { Second priority to } \\
\text { improve }\end{array}$ \\
\hline $\begin{array}{l}\text { Socialization to the community not to pollute organic } \\
\text { agricultural land with chemicals }\end{array}$ & $\mathrm{X} 10$ & $\sqrt{ }$ & & & & Priority to improve \\
\hline $\begin{array}{l}\text { Collaborate with relevant agencies to participate in the success } \\
\text { of the pilot project for organic farming }\end{array}$ & $\mathrm{X} 11$ & $\sqrt{ }$ & & & & Priority to improve \\
\hline
\end{tabular}


The development of IPA model in extension planning could definitely resolve the lack of this participatory model. The mitigation attributes which their expectation, importance, and performance come from the farmer - or according to farmer's view - could be categorized into three targets in the agricultural extension planning perspective (Table 4), namely to maintain the farmer's achievement, to remediate the main priorities, and to improve the second priority. The mitigation attributes that could be grouped into the first category include: (a) Promoting the cultivation of plant-based pesticide ingredients; (b) Training and socialization of the manufacture and use of plant-based pesticides; and (c) Weeding plants without using herbicides. The second category consists of two attributes, (a) Socialization to the community not to pollute organic agricultural land with chemicals; and (b) Collaborating with relevant agencies to participate in the success of the pilot project for organic farming. The third category has merely one attribute, which is Giving sanctions for farmers who buy chemical inputs, especially if farmers use them (Table 4).

Therefore, the subject of the program and the achievement target of the extension planning are completely based on the farmer's view. The planning should of course be executed, and in this context, by the participatory approach. However, the participatory model is not instrumental but to encourage the subject which is from, by, and for the farmers themself. The IPA model approach in the extension planning could of course improve the lack of previous participatory model.

If the participatory model - which is represented in field school model - has been developed and adopted in various fields such as in farmer entrepreneurship development [14] and small business holder extension [13], then this "farmer achievement-participatory-model" could be applied and developed in many fields of extension scopes. The organic farming (to yield the safe and healthy rice, fresh and healthy vegetable, the fresh beverage of coffee, to yield non-chemical fruit, and so on), and other field that needs extension planning could apply this model. However, it is important to discuss, despite this model has valuable advantages, it may have the disadvantage that needs to pay attention to. The process of extension planning could probably take long time, started by identifying attributes of extension planning and target, survey with representative sample, mapping of attributes, and determining the types and target of planning (to remediate as well as to maintain the attributes which are planned). It of course needs further discussion in other occasions about how to shorten this process.

\section{Conclusions and Recommendation}

Based on farmer's experience and view, this research finds six mitigation attributes that could be executed to control the risk of organic rice farming system.
Fortunately, this representative survey sample finds four attributes that the farmer expects highly to implement these attributes to control the risk of organic rice farming system; and finds two attributes that the farmer's expectation to adopt these attributes in medium level.

Regarding the performance of implementation of these attributes in farmer's experience, this research finds merely one attribute which is a high category of performance; while the research proves five attributes that take the position of medium category of its implementation performance. Based on the compatibility vs. incompatibility analysis, this research finds three attributes that could be categorized into the farmer's achievement; two attributes need highly to get improvement; and merely one attribute as the second priority to remediate.

This research finding -- and the IPA model in more broad view - could be implemented to improve the "instrumental participatory" to be the "real farmer's participatory," in which the subject of the program and the target of the extension planning is not based on the "outside" program but it is based on the "from farmer's subject" program. It will be more suitable with the agricultural extension planning for the "new comer" of millennial farmers.

\section{REFERENCES}

[1] Ajupov, A.A., M.A. Beloborodova, M.G. Sorokina, M.G., and A.A. Sherstobitova, 2016. "Risk-Management in Economic and Financial System." International Business Management, vol. 10, no. 22, 2016, pp. 5227-5231, url. https://medwelljournals.com/abstract/?doi=ibm.2016.5227.5 231

[2] Badan Pusat Statistik, "Agricultural Household Profile," The Result of Inter-Census Agricultural Survey 2018, BPS, 2018, pp. 15-47,https://docplayer.info/153172996-Hasil-sur vei-pertanian-antar-sensus-sutas2018-the-result-of-inter-cen sus-agricultural-survey-2018.html

[3] European Organic Certifier Council (2016), "Risk-assessment in organic certification: A snapshot of the current implementation and further perspectives," EOCC Task Force Risk Assessment Final Report, EOCC, Belgium, https:/eocc.nu/wp-content/uploads/2016/02/TF-RA_Final-r eport1.pdf

[4] Rogers, Everett M., Diffusion of Innovation, Third Edition, New York, The Free Press, 1983.

[5] International Federation of Organic Agricultural Movement (IFOAM), "The Principles of Organic Agriculture," The IFOAM Basic Standards for Organic Production and Processing, IFOAM, Germany, 2007, pp. 4-6,

[6] Gambelli, D., Francesco S., and Raffaele Z., "Risk assessment in EU organic certification system: a systematic literature review," Proceedings of the 4th ISOFAR Scientific Conference. 'Building Organic Bridges', at the 
Organic World Congress 2014, 13-15 Oct., Istanbul, Turkey, 2014, https://orgprints.org/id/eprint/23827/1/23827_MM.pd f

[7] Kementerian Pertanian RI, "Kementan Dorong Pertanian Organik," [Ministry of Agriculture Encourages Organic Farming System], WY, https://www.pertanian.go.id/home/? show $=$ news\&act $=$ view\&id $=3924$

[8] Maman, U., Akhmad M., Ferry J., Halal Risk Mitigation in The Australia-Indonesia Read Meat Supply Chain," Journal of Islamic Marketing, vol. 9, no. 1, 2018, pp. 60-79, https://doi.org/10.1108/JIMA-12-2015-0095

[9] Maman, U., Eka N., and Hendrik H.Y., "The Effectiveness of Farmer Field School in Dissemination of Innovation: The Case of Orchid Farmer in Tangerang Banten and Onion Farmer in Berebes Central Java," Middle East Journal of Scientific Research, vol. 23, no. 12, pp. 2927-2936, 2015, doi: 10.5829/idosi.mejsr.2015.23.12.22874

[10] Maman, U., Nunuk A, and Fahriany, Mitigation of Land Conversion Risk in Post-Harvest Phase to Optimize Staple Food Availability, Journal of Engineering and Applied Science, vol. 13, no. 8, pp. 2003-2012, 2018,

[11] Maman, U., Imam S., Nandang N.J., Zahrotun N., and Yusuf D., "The Priority of Extension Planning to Sustain Organic Farming System: The Case of Paddy Planting in Indonesia," Jour of Adv Research in Dynamical \& Control Systems, vol. 12, no. 6, pp. 2516-2523,2020, DOI: 10.5373/JARDCS/V12I6/S20201211;

[12] Maman, U., Murodi, Nindyantoro, Endin M., Dundin Z., Muhyani, Muksin, "Formulating Extension Model to Encourage Staple Food Diversification: A Solution to Food Crisis Potential," Universal Journal of Agricultural Research, vol. 9, No. 4, 2021, pp 138-148, 2021, DOI: 10.13189/ujar.2021.090405

[13] Maman, U., Iin I., and Mike S., "Adoption of Farmer Field School to Develop Entrepreneurship: The Case of Paddy Seed Growers and Small Business Trainees in Indonesia," International Conference on Science and Technology (ICOSAT 2017) in Advances in Intelligent Systems Research (AISR), vol. 149, Published by Atlantis pp. 33-37, 2018, https://www.atlantis-press.com/proceedings/icosat-17 $/ 25895970$

[14] Maman, U., Iin I., Iwan A., and Akhmad R,W., "The Need of Tailor Made Farmer Field School to Develop Entrepreneurship: The Experience from Paddy Seed Growers in Indonesia Context," Journal of Engineering and Applied Sciences, vol. 12, no. 10, pp. 2676-2681, 2017, http://docsdrive.com/pdfs/medwelljournals/jeasci/2017/267 6-2681.pdf

[15] Mustikarini, Fibria, Retnaningsih, and Megawati Simanjuntak, "Kepuasandan Loyalitas Petani Padi Terhadap Pestisida [Rice Farmers' Satisfaction and Loyalty toward Pesticides], Jur. Ilm. Kel. \& Kons. Vol 7, no. 2, pp. 93-102, 2014, DOI: https://doi.org/10.24156/jikk.2014.7.2.93

[16] Simona-Valeria T., Mioara C. and Daniela S. "Risk and Uncertainty," Procedia Economics and Finance, vol. 3, no. 3, pp. 975 - 980, 2012, https://cyberleninka.org/article/n/5036 30

[17] Sumiati, A., Julianto, Reza P.D., "Analisa Residu Pestisida di Wilayah Malang dan Penanggulanganyauntuk Keamanan
Pangan Buah Jeruk [Analysis of Pesticide Residues in the Malang Region and Management for Citrus Fruit Food Safety], Buana Sains, vol. 18, no. 2, pp. 125-130, 2018, https://cyberleninka.org/article/n/503630

[18] Sriyadi, "The Risks of Organic Rice Farming: A Case Study in The Kebonagung Village Imogiri District and Wijirejo Village Pandak District Bantul Regency, Special Region of Yogyakarta," 4th International Conference on Food and Agriculture Resources (FANRes 2018) Published by Atlantis Press, 2018, https://www.atlantis-press.com/procee dings/fanres-18/25907112

[19] Sotic, A., and Radenko R., "The Review of the Definition of Risk." Online Journal of Applied Knowledge Management. vol. 3, no. 3, pp. 17-26, 2015, http://www.iiakm.org/ojakm/ articles/2015/volume3_3/OJAKM_Volume3_3pp17-26.pdf

[20] Puspitasari and Adhitya M. K., "Perilaku Petanidalam Menggunakan Pestisida di Sentra Produksi Bawang Merah Kabupaten Brebes" [Farmer's Behavior in Using Pesticides in the Shallots Production Center in Brebes Regency], Proceedings of the National Location-Specific Agroinovation Seminar for Food Security in the Era of the ASEAN Economic Community, 2017, http://repository.pert anian.go.id/handle/123456789/7303

[21] Omar R., and Jamilah D., "Risk Assessment Tool for Software Project in Malaysian Public Sector." Journal of Engineering and Applied Sciences, vol. 12, no. 3, pp. 527-533, http://docsdrive.com/pdfs/medwelljournals/jeasci/ 2017/527-533.pdf

[22] Olayemi, S.S., Alo A. O. and Angba C.W. "Evolution of Agricultural Extension Model, International Journal of Agricultural Extension and Rural Development Studies, vol.8, no.1, pp.29-51, 2021, https://www.eajournals.org/wpcontent/uploads/Evolution-of-Agricultural-Extension-Model s-in-Sub-Saharan-Africa.pdf

[23] Wahanisa, R., Aprila N., Muh. Afif M., Siti Aminah, "Public Participation by Optimizing Rural Spatial Planning to Prevent Functional Conversion of Agricultural Land to Non-agricultural Use," Universal Journal of Agricultural Research, Vol. 9, No. 5, 2021, pp. 149-155, DOI: 10.13189/ujar.2021.090501

[24] Prayoga, K., Adietya M. R., Aditya R,S., Dimas S. P., "Socio cultural and agricultural local wisdom by cetho indigenous community to preserve the nature, AGROMIX, vol. 11, no. 1, pp. 21-32, 2020, DOI: https://doi.org/10.3589 1/agx.v11i1.1843.

[25] Sagala, J.L.B., Evasaria M. S., Arief S. G., "Pengembangan Sistem Penilaian Kualitas Pelayanan dengan Metode Importance Performance Analysis," Jurnal Telematika, vol. 8, no. 1, pp. 22-28, 2013, https://journal.ithb.ac.id/telematik a/article/view/67

[26] Ormanović, S., Alen Ć., Munir T., Haris A., Eldin J., Denis C.., "Importance-Performance Analysis: Different Approaches, ActaKinesiologica, Vol. 11, No. 2, 2017, pp. 58-66, https://www.researchgate.net/publication/322790903 IMPORTANCE-PERFORMANCE ANALYSIS_DIFFER ENT_APPROACHES

[27] Eliza, T. Tubagus H., Suriaty S., "Farmers' Behavior In Chemical Pesticides Use: Case of Chili Crop Farmers at Gisting Atas Village, Gisting District, Tanggamus Regency," 
JIIA, Vol. 1, No. 4, pp. 334-342, 2013, https://123dok.com/document/qmvlkj4q-perilaku-pengguna an-pestisida-gisting-kecamatan-gisting-kabupaten-tanggamu s.html\#google_vignette
[28] Allahverdi, H.T., Mammadova G.I., Bunyatova L.N., Gahramanova A.Y., "Importance of Biodiagnostics and Irrigation Gray-Brown Soils," Universal Journal of Agricultural Research, vol. 9, no. 3, pp. 63-69, 2021. DOI: 10.13189/ujar.2021.090301 